\title{
Child Benefit and Fiscal Burden: OLG Model with Endogenous Fertility
}

\author{
Kazumasa Oguro, Junichiro Takahata, Manabu Shimasawa \\ Associate Professor, Hitotsubashi University, Tokyo, Japan \\ Research Associate, JICA Research Institute, Tokyo, Japan. \\ Associate Professor, Akita University, Akita, Japan \\ E-mail:ZVU07057@nifty.com,Takahata.Junichiro.2@jica.go.jp,mshimasawa@ed.akita-u.ac.jp \\ Received May 31, 2011; revised July 12, 2011; accepted July 22, 2011
}

\begin{abstract}
In this paper, we present an OLG simulation model with endogenous fertility to analyze the relationship between child benefit and fiscal burden. Our simulation results show that expansion of the child benefit will improve the welfare of current and future generations. On the other hand, our findings show that we cannot expect a significant long-term improvement in welfare solely from the increase of the consumption tax. If both the fiscal sustainability and the improvement of the welfare of current and future generations are requirements, we will need a policy-mix that includes both child benefit expansion and additional fiscal reform.
\end{abstract}

Keywords: Computable General Equilibrium (CGE) Model, Overlapping Generations (OLG), Child Benefit, Endogenous Fertility

\section{Introduction}

Developed countries currently face unprecedented demographic changes which require extensive reform in fiscal systems, social security systems, and other related programs. However, due to conflicting interests between younger and older generations, reform may be restricted. As an example of a pay-as-you-go pension, in order to improve the sustainability of the system, the government has the option of reducing the benefits to the elderly or increasing the burden on the working generation. Obtaining agreement on reform by both generations is often too difficult for the government to achieve. In this situation, some developed countries such as France have proceeded with the expansion of child benefit programs. These programs are expected to increase the population of the younger generation as a tax resource and, as result, to reduce the per capita fiscal burden in the future.

In this paper we analyze the relationship between child benefit and the fiscal burden in the setting of an overlapping generations (OLG) model. In the process of this analysis, it is important for us to distinguish between an exogenous fertility model and an endogenous fertility model. The reason is that recent studies have clarified that the Pareto-efficiency condition of the exogenous fertility model differs from that of the endogenous fertility model. First, for an exogenous fertility model, we use the OLG model introduced by Diamond [1]. Three types of steady states exist in the model: under-accumulation, golden rule, and over-accumulation. The first two steady states are Pareto-efficient, but the third is not. In addition, an empirical study by Abel et al. [2] reports that in industrialized countries dynamic efficiency is satisfied. In a steady state, dynamic efficiency corresponds to under-accumulation (or golden rule). Therefore, the possibility that developed countries are in a state of under-accumulation seems high. In an exogenous fertility setting, an allocation is said to be Pareto-efficient if it is impossible to make some individuals better off without making other individuals worse off. For this reason, in an exogenous case, we cannot improve any generation's utility while at the same time sacrificing another generation's utility.

However, recent studies clarify the properties of the competitive equilibrium with an endogenous fertility setting. Raut and Srinivasan [3] and Charkrabarti [4] analyze the properties of intertemporal equilibrium with endogenous fertility. Conde-Ruiz et al. [5] and Golosov et al. [6] present the definition of Pareto-efficiency criteria in an endogenous fertility framework. 
As a development of these studies, Michel and Wigniolle $[7]^{1}$ point out the possibility that under-accumulation may not be efficient in an endogenous fertility setting. This implies that some policies could effect improvement in one generation's welfare without sacrificing another generation's welfare, even when it is in an underaccumulation state near the steady state. Moreover, the remarkable point made by Michel and Wigniolle [7] is to clarify that the Representative-Consumer efficient (RCefficient) condition, which is a concept developed in their study, has a profound connection with the sign-of-inequality relationship between the child-rearing cost and wage rate. ${ }^{2}$ That is, if some policies do provide effects to this relationship, improvement in RC-efficiency becomes possible. Michel and Wigniolle [7] provide proof that, by utilizing an OLG model with endogenous population growth, the possibility to improve RC-efficiency also exists in the case of under-accumulation. But they did not analyze an economy model with public debt. Therefore, Oguro and Takahata [13] analyze the relationship between child benefit and fiscal burden, in the setting of an OLG model with both endogenous fertility and public debt, and provide the condition of RC-efficiency. However, they also could not analyze the relationship between child benefit and fiscal burden in a real economy. The reason is that the overlapping generations of their OLG model amount to only two: the working generation and the retired generation. To analyze the relationship in a real economy, it is necessary to build an OLG model with more overlapping generations: e.g., a model with 85 overlapping generations and endogenous fertility.

To this end, we construct a large-scale numerical dynamic equilibrium OLG model with endogenous fertility, which is calibrated to the Japanese economy. And we quantitatively evaluate the effects of child benefit change: e.g., the effects on the welfare of multiple generations. By doing this, we attempt to answer whether a fundamental change in child benefit policy results in significant positive effects on the Japanese economy, especially in terms of the government fiscal situation.

The structure of this paper is as follows. In Section 2, we describe the model structure; Section 3 presents the calibration strategy and the findings; Section 4 describes simulation results, and Section 5 contains concluding remarks and policy implications.

\footnotetext{
${ }^{1}$ Although there have been several approaches that endogenize fertility decisions, Michel and Wigniolle [7] depend on the benchmark framework, which assumes that children are consumption goods that appear in the utility function of the parents. The basic articles are Becker [8], Willis [9], and Eckstein and Wolpin [10]. Other approaches depend on the literature based on the additional assumption of descendant altruism as in Becker and Barro [11] or the assumption of ascendant altruism and strategic behavior of parents, as in Nishimura and Zhang [12].

${ }^{2}$ The definition of "RC-efficiency" can be seen in Michel and Wigniolle [7] or Oguro and Takahata [13].
}

\section{The Model Structure}

In this section, we describe the demographic and economic structure of our model. The model used here is a computable general-equilibrium OLG model with perfect foresight agents, multiple periods, and endogenous fertility. In our model, there is a representative individual for each generation in the households sector. Each individual at age 20 maximizes his/her intertemporal utility function with consumption and number of children. The representative competitive firm has a standard Cobb-Douglas production technology and maximizes its profits. In our model, not only the goods market but also factor markets are perfectly competitive. The model has five main building blocks: 1) household behavior, 2) firm behavior, 3) the Government, 4) the public pension, and 5) market equilibrium. Details of each block follow.

\subsection{Household Behavior}

There is a representative individual for each generation in the household sector. We assume that preferences forms are the same for all agents in all generations. Moreover, each individual lives for a fixed number of periods. In each period of the model, the oldest generation dies and a new one enters. And the representative individuals maximize their intertemporal utility function with consumption and number of their children subject to their lifetime income. They are also assumed to be rational, having perfect foresight. Each generation enters the labor market at age 21 , bears and brings up their children at ages 21 to $M+20$, retires at age $Q-1$, is granted a pension at $Q$, and dies at age $Z$. In addition, each supplies labor inelastically. The within-period utility function exhibits constant relative risk aversion, and preferences are additive and separable over time. In each region, the utility functions of the $t$ th generation born in year $t$ are specified as: $:^{3}$

$$
U_{t}=\alpha \frac{n_{t}^{1-\sigma_{1}}}{1-\sigma_{1}}+(1-\alpha) \sum_{j=1}^{Z-20}\left(\frac{1}{1+\rho}\right)^{j} \frac{c_{t, j}^{1-\sigma_{2}}}{1-\sigma_{2}}
$$

where $\alpha$ refers to the weight between number of children and consumption, $\sigma_{1}$ the preference parameter of number of children, $j$ the $j$ th period of life, $\rho$ the pure rate of time preference, and $\sigma_{2}$ the reverse of the elasticity of intertemporal substitution of consumption. The arguments of the utility function are the number of children $\left(n_{t}\right)$ and the consumption per period $\left(c_{t, j}\right)$. Leisure does not enter the utility function since the individual's labor supply is assumed to be exogenous.

${ }^{3}$ This is the expansion of the utility function provided by Groezen et al.
[14]. If $\sigma_{1}=\sigma_{2}=1$ and $Z=22$, i.e. only two periods (working period
and retired period), this utility function becomes the same form as that of Groezen et al. [14]. 
In addition, we assume that the number of children $\left(n_{t, j}\right)$ whom the $t$ th generation bears at the $j$ th period of life is the following:

$$
\begin{aligned}
& n_{t, j}=p_{j} n_{t} \\
& \text { (where } p_{j}>0 \quad(\text { if } \quad 1 \leq j \leq M-20) \\
& \text { and } \left.p_{j}=0 \quad(\text { if } j>M-20)\right)
\end{aligned}
$$

where $p_{j}$ refers to the possibility that each generation bears the children at the $j$ th period of life and this parameter is assumed to be exogenous.

Moreover, the technological progress $\lambda$ is assumed to be exogenous and labor embodied. We model agespecific labor productivity by assuming a hump-shaped age-earnings profile, i.e., a quadratic form of its age $j$, so its age-wage profile $e_{j}$ takes the following form:

$$
\begin{aligned}
& e_{j}=\varsigma_{0}+\varsigma_{1} j+\zeta_{2} j^{2} \\
& \zeta_{0}, \zeta_{1} \geq 0 \text { and } \zeta_{2} \leq 0
\end{aligned}
$$

The intertemporal budget equation of each generation is described as follows:

$$
\begin{aligned}
& \sum_{j=1}^{M-20} \sum_{g=1}^{20} \frac{\varphi_{g}\left(1-\theta_{t+j-1+g+20}\right) n_{t, j}}{\prod_{k=1}^{j-1+g}\left(1-t r_{t+k+20}\right) R_{t+k+20}} \\
& +\sum_{j=1}^{Z-20} \frac{\left(1+t c_{t+j+20}\right) c_{t, j}}{\prod_{k=1}^{j}\left(1-t r_{t+k+20}\right) R_{t+k+20}}=N W_{t} \\
& \equiv \sum_{j=1}^{Q-21} \frac{\left(1-t w_{t+j+20}-\tau w_{t+j+20}\right) w_{t+j+20}(1+\lambda)^{t+j+20} e_{j}}{\prod_{k=1}^{j}\left(1-t r_{t+k+20}\right) R_{t+k+20}} \\
& +\sum_{j=Q-20}^{Z-20} \frac{\left(1-\tau p_{t+j+20}\right) q_{t+j+20}}{\prod_{k=1}^{j}\left(1-t r_{t+k+20}\right) R_{t+k+20}}
\end{aligned}
$$

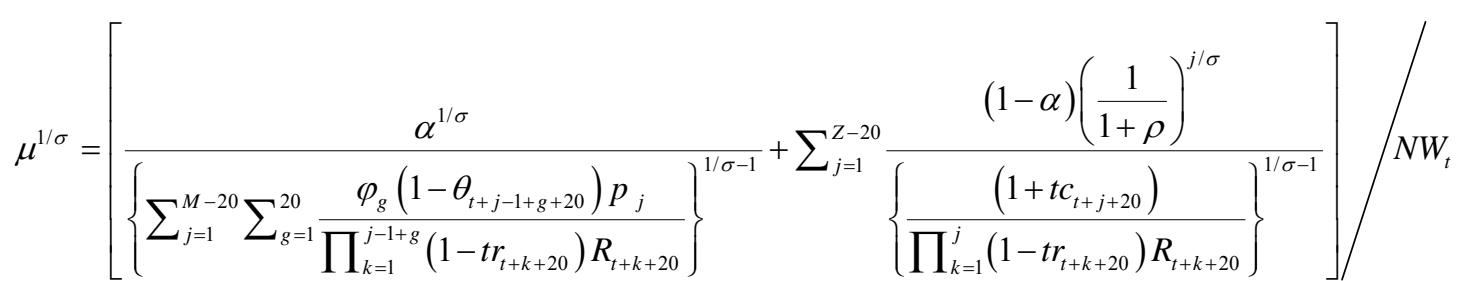

If the parameter $\mu$ is stable, these equations dictate the following two relationships: 1) as in any life-cycle model, the trade-off between current and future consumption is determined by the ratio of the interest rate and the time preference rate, and by the degree of risk aversion, and 2) the number of children declines, when the child rearing cost increases or the government subsidy decreases. Moreover, from these equations, the following forms can be shown:

$$
C_{t}=\sum_{j=1}^{Z-20} N_{t} c_{t-j-20, j}, N_{t}=\sum_{j=1}^{M-20} N_{t} n_{t-j-20, j}
$$

where $C_{t}$ is the aggregated consumption in year $t$, and where $1 / \prod(1-t r) R$ refers to the factor of the present discounted value which is driven from the gross interest rate $R_{t}$ and the capital tax $\operatorname{tr}_{t}$ in year $t, \varphi_{g}$ is the child rearing cost at the $g$ th period of life, $\theta_{t}$ is the government subsidy in year $t, t c_{t}$ is the consumption tax rate in year $t, t w_{t}$ is the labor income tax rate in year $t, \tau w_{t}$ is the public pension contribution rate in year $t, N W_{t}$ is the net lifetime income of generation $t, w_{t}$ is the wage rate in year $t, \tau p_{t}$ is the tax for pension benefit in year $t$, and $q_{t}$ stands for pension benefit in year $t$. In addition, child rearing cost is assumed to be proportional to net lifetime income, i.e., $\varphi_{g}=\Phi_{g} N W_{t}$, where $\Phi_{g}$ is the constant parameter.

Each generation maximizes its utility function (1) under the budget constraint (4).

When $\sigma \equiv \sigma_{1}=\sigma_{2}$, the maximization procedure differentiating the household utility function (2) with respect to $n_{t}$ and $c_{t, j}$, subject to the individual's lifetime budget constraint (4), yields the following equations concerning consumption per period and number of children.

$$
\begin{gathered}
c_{t, j}=\left\{(1-\alpha)\left(\frac{1}{1+\rho}\right)^{j} / \mu \frac{\left(1+t c_{t+j+20}\right)}{\prod_{k=1}^{j}\left(1-t r_{t+k+20}\right) R_{t+k+20}}\right\}^{1 / \sigma}, \\
n_{t}=\left\{\alpha / \mu \sum_{j=1}^{M-20} \sum_{g=1}^{20} \frac{\varphi_{g}\left(1-\theta_{t+j-1+g+20}\right) p_{j}}{\prod_{k=1}^{j-1+g}\left(1-t r_{t+k+20}\right) R_{t+k+20}}\right\}^{1 / \sigma},
\end{gathered}
$$

and

$N_{t}$ measures the number of the generation born in year $t$. In addition, we can also derive the following physical wealth accumulation equation:

$$
\begin{aligned}
& a_{t, j}=a_{t, j-1}\left(1-t r_{t+(j-1)+20}\right) R_{t+(j-1)+20} \\
& +\left(1-t w_{t+j+20}-\tau w_{t+j-20}\right) w_{t, j} \\
& -\left(1+t c_{t+j+20}\right) c_{t, j}-\sum_{g=1}^{j} \varphi_{g}\left(1-\theta_{t+j+20}\right) n_{t, j-g+1}, \\
& \text { and } P A_{t}=\sum_{j=1}^{Z-20} N_{t} a_{t-j-20, j}
\end{aligned}
$$

where $a_{t, j}$ is physical wealth asset of generation $t$ at the $j$ th period of life, and $P A_{t}$ is the aggregated private 
asset in year $t$.

\subsection{Firm behavior}

The input/output structure is represented by the CobbDouglas production function with constant return to scale. The firm decides the demand for physical capital and effective labor in order to maximize its profit with the given factor prices of wage and rent, which are determined in the perfect competitive markets.

$$
\begin{gathered}
Y_{t}=A K_{t}^{\varepsilon} L_{e, t}^{1-\varepsilon} \\
L_{e, t} \equiv \sum_{j=1}^{Q-20}(1+\lambda)^{t} e_{j} N_{t-j-20}, \\
K_{t}=I_{t}+(1-\delta) K_{t-1}
\end{gathered}
$$

where $Y_{t}$ is output, $\varepsilon$ stands for capital income share, $A$ is a scale parameter, $K_{t}$ is the physical capital stock, and $L_{e, t}$ is the effective labor.

We can derive two factor prices, the rate of return $r_{t}$ and the wage rate per unit of effective labor $w_{t}$, by the first-order conditions for the firm's maximum profit:

$$
\begin{aligned}
& R_{t} \equiv 1+r_{t}=\varepsilon A K_{t}{ }^{\varepsilon-1} L_{e, t}{ }^{1-\varepsilon}+(1-\delta) \\
& w_{t}=(1-\varepsilon) A K_{t}^{\varepsilon} L_{e, t}{ }^{-\varepsilon}
\end{aligned}
$$

where $\delta$ is the depreciation of physical capital.

\subsection{The public pension}

The pension sector grants a pension to the retirement generations while pension contribution is collected from the working generations.

$$
P_{t}=\tau w_{t} \times w_{t} L_{e, t}
$$

where $P_{t}$ stands for the aggregated pension contribution.

The aggregated pension benefits in year $t$ is given by the product of the population of retirement age, replacement rate, and average earnings of each generation during the working period $\bar{W}_{t}$.

$$
B_{t}=\sum_{j=Q-19}^{Z-20} q_{t+j+20} N_{t+j+20}=\sum_{j=Q-19}^{Z-20} \gamma \times \bar{W}_{t+j+20} N_{t+j+20}
$$

where $\gamma$ denotes replacement rate and $B_{t}$ is the aggregated pension benefit.

We explicitly model the public pension system as payas-you-go. The budget constraint of the pension sector can be shown as follows:

$$
P_{t}=(1-s p) B_{t}
$$

where spdenotes public subsidy to pension, which is financed by government expenditure $G_{t}$.

Moreover, we assume that the public pension sector maintains a fixed replacement rate exogenously. As a result, in our model, the pension contribution rate is endogenously determined in order to keep the budget constraint (13).

\subsection{The Government}

The government sector has four types of taxes: wage tax, consumption tax, capital tax, and pension benefit tax, and the public debt issue income as its revenue and pays the consumption, investment, and interest payments as expenditures.

$$
T_{t}=t w_{t} \times w_{t} L_{e, t}+t c_{t} \times C_{t}+t r_{t} \times R_{t} \times P A_{t}+t p_{t} \times B_{t}
$$

We keep all tax rates constant. The role of the government is to endogenously determine the rate of the public debt issue as a residual of government expenditure and revenue.

$$
D_{t}=G_{t}-T_{t}+\left(1+r_{t}\right) D_{t-1}
$$

where $G_{t}$ stands for government expenditure in year $t$, $T_{t}$ denotes tax revenue in year $t, D_{t}$ denotes public debt in year $t$.

The public debt issue Bond $_{t} \equiv D_{t}-\left(1+r_{t}\right) D_{t-1}$ is set endogenously due to the difference between expenditure and tax revenue. It should be noted that the public debt issue to GDP ratio will change over time as a result of possible imbalances between revenues and expenditures. Thus we don't know whether the fiscal policy of a country is sustainable and whether the government's intertemporal budget constraint must be satisfied.

\subsection{Market Equilibrium}

Finally, in our model of a closed economy, we require the equilibrium in the financial market, i.e., the aggregate value of assets equals the market value of the capital stocks plus the value of outstanding government bonds:

$$
P A_{t}=K_{t}+D_{t}
$$

\section{The Data, Calibration, and Scenarios}

\subsection{Data and Calibration}

First, we present the values of the main parameters and exogenous variables of the model in Table 1. The parameter values for the households' and firms' behaviors are derived from Auerbach and Kotlikoff [15] and various early OLG simulation studies in Japan. ${ }^{4}$ These parameters, such as technological and preference parameters except the weight parameter $\alpha$, are assumed to be constant.

\footnotetext{
${ }^{4}$ See Sadahiro and Shimasawa [16,17]; Uemura [18]; and Ihori et al. [19].
} 
Table 1. Parameter Values of the Model.

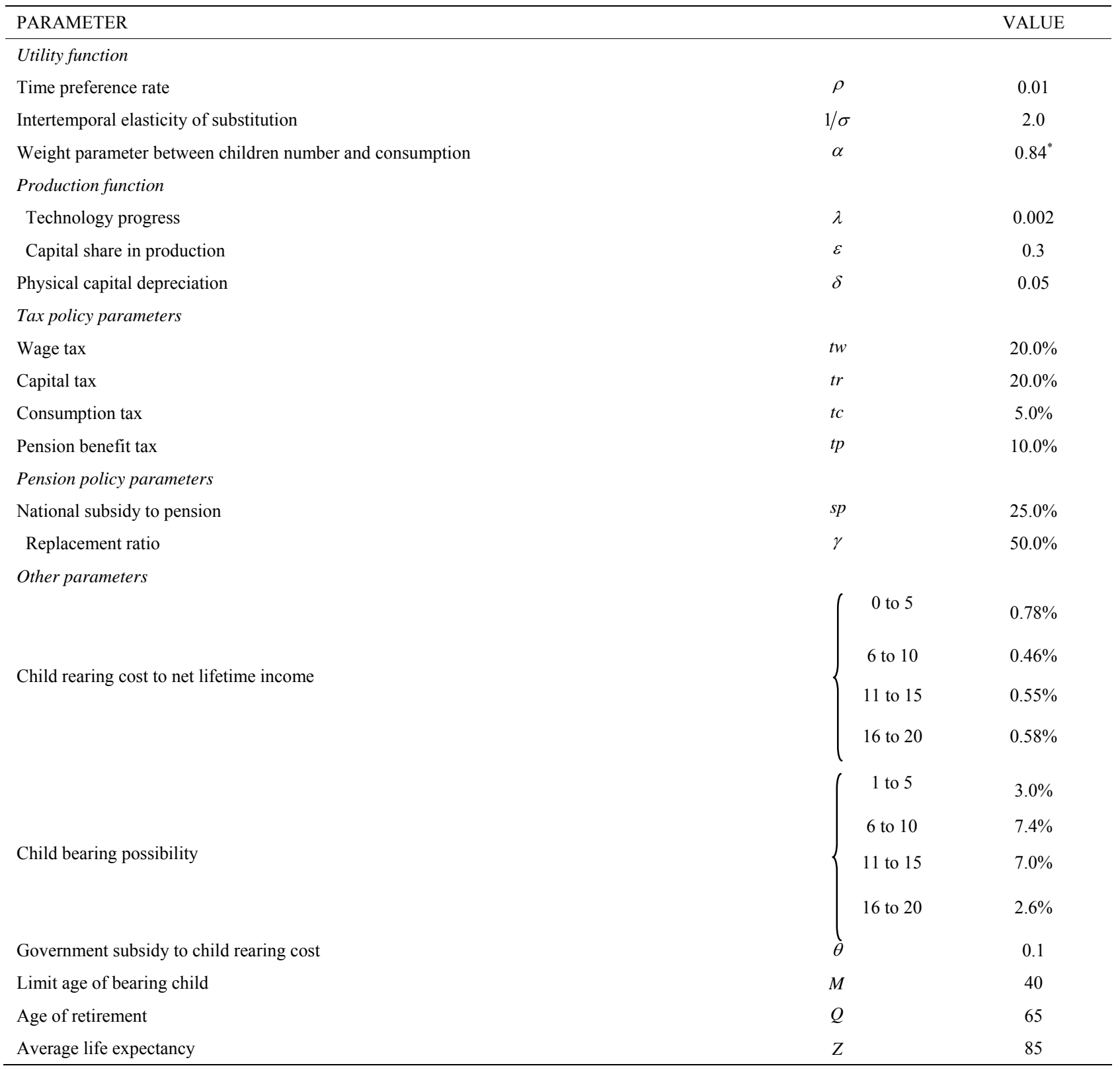

* This parameter is fixed after year 2007.

The exogenous variables such as the macroeconomic, fiscal, and public pension variables are derived mainly from OECD [20] "Tax Database," and Whitehouse [21] "Pensions Panorama."

In addition, the child bearing possibility parameter is derived from the data of "Age-specific fertility rate," which is provided by the National Institute of Population and Social Security Research [22], and the parameter values of the child rearing cost and the government subsidy are derived from the special research report about social cost of rearing children, which is provided by the Cabinet Office Director-General for Policies on a Cohe- sive Society, Japan [23].

Second, by controlling the weight parameters in years $1900-2007$, we calibrate our demographic projection to fit the data's trend in "Population by Age (generation born in 1900 - 2007)," which is provided by the Statistics Bureau, Ministry of Internal Affairs and Communications with the collaboration of other Ministries and Agencies in Japan. Figure 1 reports the actual values and the computed values of demographic projection. Note that actual and calculated values correspond closely.

Next, in order to analyze the relationship between child benefit and fiscal burden, we start our calculations 


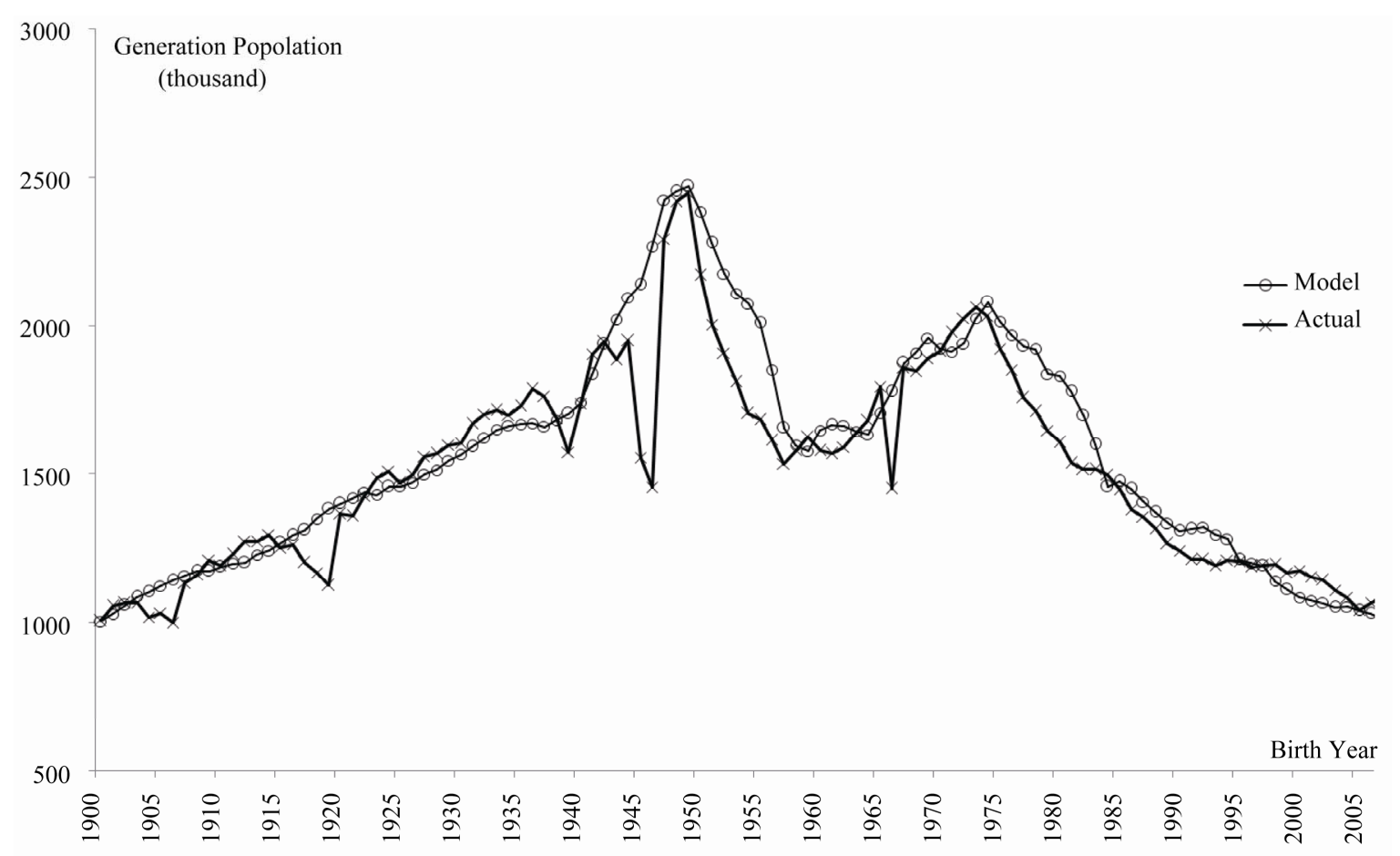

Figure 1. Demographic Projection of Each Generation.

with a phase-in period of about 200 years in order to relax the unrealistic assumption of a steady state in the 2007 base year of our simulation. Moreover, since the model is simulated over 500 periods, we ensure a sufficiently long period for a steady state to be achieved.

Table 2 reports the actual values of some key variables in 2007 and the computed values in the model. Also, note that actual and calculated values correspond closely.

\subsection{Scenarios}

Next we present simulation scenarios (See Table 3). The scenarios are classified into four categories. Scenario 1 assumes the baseline case with no expansion of child benefit, and Scenarios 2 and 3 assume 100\% increase of child benefit after 2015. Scenario 4 assumes 50\% increase of child benefit after 2015. Scenarios 5 and 6 assume no expansion of child benefit but an increase in the consumption tax to $10 \%$ and $15 \%$ (consumption tax reform), respectively. Finally, Scenario 7 is the policy-mix of Scenario 2 (permanent expansion) and Scenario 6 (15\% consumption tax reform).

In Scenarios 2 and 4, the increase of child benefit is permanent from 2015. In Scenario 3, the increase of child benefit is temporal for 2015-2025.

\section{Simulation Results}

We now turn to describe the simulation results reported in Figures 2 to 5 and Table 4. Here we present the scenarios of results of the child benefit expansion in comparison to the cases of no expansion, the case of consumption tax reform, and the case of policy-mix (permanent expansion and consumption tax reform).

\subsection{Demographic Projection and Macroeconomic Variables}

Figure 2 shows the population projection of future generations born in 2000 - 2030. The projection of Scenario 1 and official estimation, which is provided by the National Institute of Population and Social Security Research [23], closely correspond. In Scenario 2 (100\% permanent child benefit increase), compared with Scenario 1, the population of the generation born in 2030 increases by 143,000 , in Scenario 3 (100\% temporally child benefit increase) by 11,000 , in Scenario $4(50 \%$ permanent child benefit increase) by 66,000 , in Scenario 5 (10\% consumption tax reform) by $-4,000$, in Scenario 6 (15\% consumption tax reform) by 19,000 , and in Scenario 7 (policy-mix) by $166,000 .^{5}$

Figure 3 also shows the retired population ratio. The ratio of Scenario 1 and official estimation, which is provided by the National Institute of Population and Social

${ }^{5}$ Consumption tax reform may contribute to the increase of population of future generations through the mechanism in that the fall in net lifetime income decreases the child rearing cost, e.g., the opportunity cost which is the net lost income when parents bring up a child. 
Table 2. Year 2007 of the Baseline Scenario.

\begin{tabular}{|c|c|c|}
\hline & OFFICIAL & MODEL \\
\hline \multicolumn{3}{|l|}{ National Income (\% of GDP) } \\
\hline Private consumption & $74.1 \%$ & $81.3 \%$ \\
\hline Government purchases of goods and services & $21.0 \%$ & $24.3 \%$ \\
\hline Saving rate & $3.1 \%$ & $6.1 \%$ \\
\hline \multicolumn{3}{|l|}{ Government Indicators } \\
\hline Pension premium to wage & $14.9 \%$ & $14.9 \%$ \\
\hline Gross public debt (\% of GDP) & $170.6 \%$ & $170.6 \%$ \\
\hline Primary balance (\% of GDP) & $-2.4 \%$ & $-4.5 \%$ \\
\hline Tax revenues (\% of GDP) & $18.4 \%$ & $19.8 \%$ \\
\hline \multicolumn{3}{|l|}{ Other Indicators } \\
\hline Capital output ratio & 2.9 & 4.6 \\
\hline Interest rate & $1.7 \%$ & $2.6 \%$ \\
\hline
\end{tabular}

Data source: Official values are derived from OECD Economic Outlook No. 84, 2008 and "Annual Report on National Accounts," the Japanese SNA statistics (Cabinet Office).

Table 3. Scenarios.

\begin{tabular}{|c|c|c|c|c|c|c|c|}
\hline & Scenario 1 & Scenario 2 & Scenario 3 & Scenario 4 & Scenario 5 & Scenario 6 & Scenario 7 \\
\hline Child benefit & No increase & $\begin{array}{c}100 \% \text { increase after } \\
2015\end{array}$ & $\begin{array}{c}100 \% \text { increase for } \\
2015-25\end{array}$ & $\begin{array}{c}50 \% \text { increase after } \\
2015\end{array}$ & No increase & No increase & $\begin{array}{l}100 \% \text { increase } \\
\text { after } 2015\end{array}$ \\
\hline Consumption tax & $5 \%$ & $5 \%$ & $5 \%$ & $5 \%$ & $10 \%$ & $15 \%$ & $15 \%$ \\
\hline
\end{tabular}

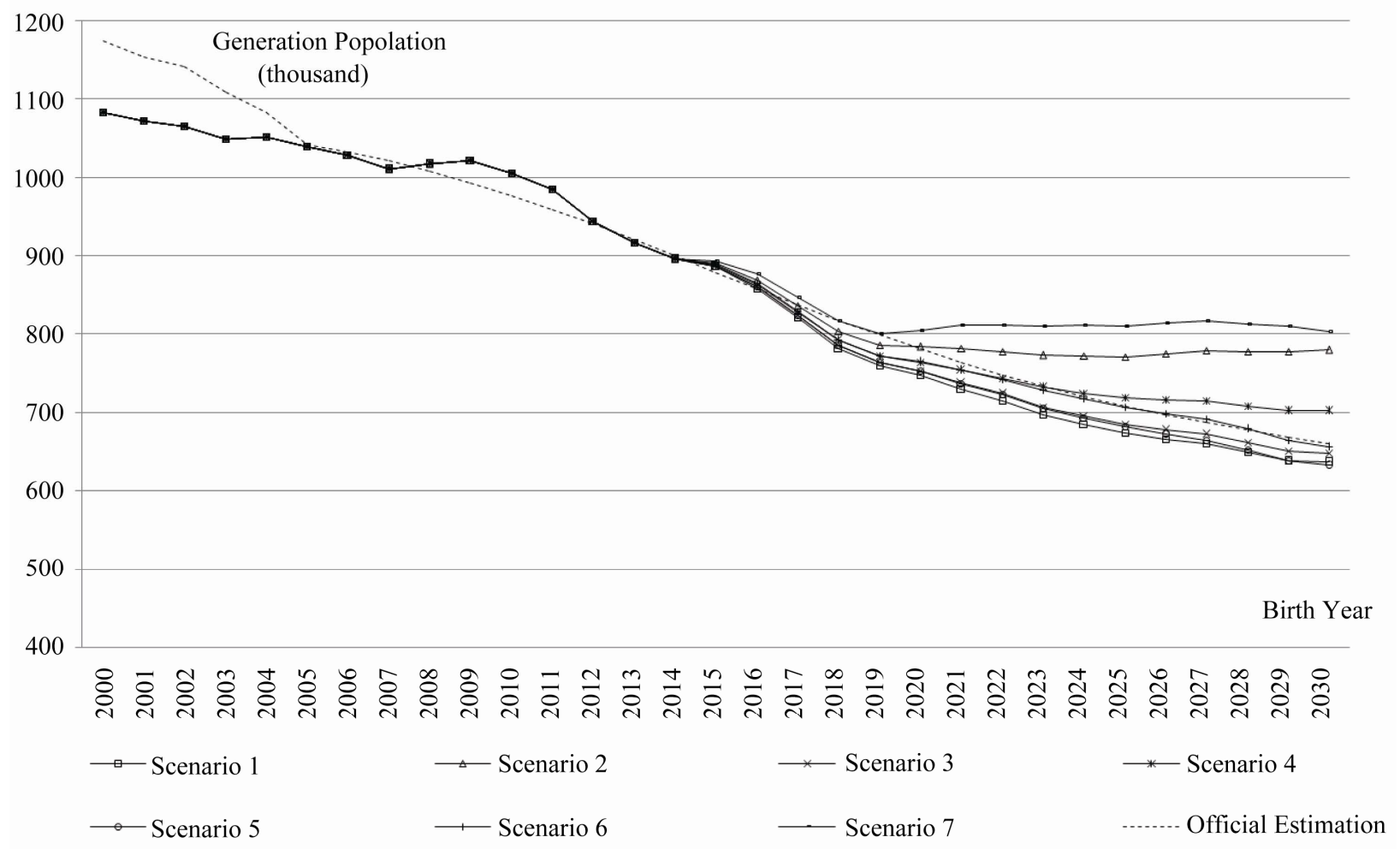

Figure 2. Simulation Results-Demographic Projection of Future Generation. 
Table 4. Simulation Results-Macro Economic Projection.

\begin{tabular}{|c|c|c|c|c|c|c|c|c|c|c|}
\hline & & GDP & $\begin{array}{l}\text { GDP per } \\
\text { employee }\end{array}$ & $\begin{array}{l}\text { Saving } \\
\text { rate }\end{array}$ & $\begin{array}{l}\text { Capital- } \\
\text { labor ratio }\end{array}$ & $\begin{array}{l}\text { Interest } \\
\text { rate }\end{array}$ & Wage rate & $\begin{array}{l}\text { Debt-GD } \\
\text { P ratio }\end{array}$ & $\begin{array}{l}\text { Debt per } \\
\text { employee }\end{array}$ & $\begin{array}{c}\text { Pension } \\
\text { premium } \\
\text { to wage }\end{array}$ \\
\hline \multirow[t]{4}{*}{ Scenario 1} & 2007 & $100.00 \%$ & $100.00 \%$ & $6.17 \%$ & $100.00 \%$ & $2.61 \%$ & $100.00 \%$ & $170.65 \%$ & $100.00 \%$ & $14.90 \%$ \\
\hline & 2010 & $98.63 \%$ & $101.30 \%$ & $5.59 \%$ & $101.82 \%$ & $2.51 \%$ & $100.54 \%$ & $186.94 \%$ & $108.02 \%$ & $15.83 \%$ \\
\hline & 2015 & $94.49 \%$ & $104.03 \%$ & $5.82 \%$ & $104.68 \%$ & $2.37 \%$ & $101.38 \%$ & $219.79 \%$ & $123.21 \%$ & $17.37 \%$ \\
\hline & 2030 & $80.75 \%$ & $103.92 \%$ & $1.16 \%$ & $95.61 \%$ & $2.85 \%$ & $98.66 \%$ & $364.40 \%$ & $192.97 \%$ & $26.45 \%$ \\
\hline \multirow[t]{5}{*}{ Scenario 2} & 2007 & $100.00 \%$ & $100.00 \%$ & $6.17 \%$ & $100.00 \%$ & $2.61 \%$ & $100.00 \%$ & $170.79 \%$ & $100.00 \%$ & $14.90 \%$ \\
\hline & 2010 & $98.63 \%$ & $101.30 \%$ & $5.59 \%$ & $101.82 \%$ & $2.51 \%$ & $100.54 \%$ & $187.15 \%$ & $108.06 \%$ & $15.83 \%$ \\
\hline & 2015 & $94.51 \%$ & $104.05 \%$ & $6.06 \%$ & $104.74 \%$ & $2.36 \%$ & $101.40 \%$ & $220.38 \%$ & $123.46 \%$ & $17.37 \%$ \\
\hline & 2020 & $90.33 \%$ & $106.20 \%$ & $0.95 \%$ & $105.57 \%$ & $2.32 \%$ & $101.64 \%$ & $261.87 \%$ & $142.96 \%$ & $25.99 \%$ \\
\hline & 2030 & $80.66 \%$ & $103.81 \%$ & $1.49 \%$ & $95.27 \%$ & $2.87 \%$ & $98.56 \%$ & $371.39 \%$ & $194.48 \%$ & $26.48 \%$ \\
\hline \multirow[t]{5}{*}{ Scenario 3} & 2007 & $100.00 \%$ & $100.00 \%$ & $6.17 \%$ & $100.00 \%$ & $2.61 \%$ & $100.00 \%$ & $170.77 \%$ & $100.00 \%$ & $14.90 \%$ \\
\hline & 2010 & $98.63 \%$ & $101.30 \%$ & $5.59 \%$ & $101.82 \%$ & $2.51 \%$ & $100.54 \%$ & $187.12 \%$ & $108.05 \%$ & $15.83 \%$ \\
\hline & 2015 & $94.49 \%$ & $104.03 \%$ & $6.05 \%$ & $104.69 \%$ & $2.37 \%$ & $101.39 \%$ & $220.33 \%$ & $123.43 \%$ & $17.37 \%$ \\
\hline & 2020 & $90.31 \%$ & $106.18 \%$ & $0.93 \%$ & $105.52 \%$ & $2.33 \%$ & $101.63 \%$ & $261.71 \%$ & $142.97 \%$ & $25.99 \%$ \\
\hline & 2030 & $80.67 \%$ & $103.82 \%$ & $1.24 \%$ & $95.30 \%$ & $2.87 \%$ & $98.57 \%$ & $369.45 \%$ & $195.11 \%$ & $26.48 \%$ \\
\hline \multirow[t]{4}{*}{ Scenario 4} & 2007 & $100.00 \%$ & $100.00 \%$ & $6.17 \%$ & $100.00 \%$ & $2.61 \%$ & $100.00 \%$ & $170.72 \%$ & $100.00 \%$ & $14.90 \%$ \\
\hline & 2010 & $98.63 \%$ & $101.30 \%$ & $5.59 \%$ & $101.82 \%$ & $2.51 \%$ & $100.54 \%$ & $187.05 \%$ & $108.04 \%$ & $15.83 \%$ \\
\hline & 2020 & $90.33 \%$ & $106.20 \%$ & $0.81 \%$ & $105.58 \%$ & $2.32 \%$ & $101.64 \%$ & $260.70 \%$ & $142.45 \%$ & $25.99 \%$ \\
\hline & 2030 & $80.71 \%$ & $103.87 \%$ & $1.31 \%$ & $95.45 \%$ & $2.86 \%$ & $98.61 \%$ & $367.70 \%$ & $193.71 \%$ & $26.46 \%$ \\
\hline \multirow[t]{5}{*}{ Scenario 5} & 2007 & $100.00 \%$ & $100.00 \%$ & $6.17 \%$ & $100.00 \%$ & $2.61 \%$ & $100.00 \%$ & $170.49 \%$ & $100.00 \%$ & $14.90 \%$ \\
\hline & 2010 & $98.63 \%$ & $101.30 \%$ & $5.59 \%$ & $101.82 \%$ & $2.51 \%$ & $100.54 \%$ & $186.71 \%$ & $107.98 \%$ & $15.83 \%$ \\
\hline & 2015 & $92.39 \%$ & $101.72 \%$ & $6.86 \%$ & $97.14 \%$ & $2.76 \%$ & $99.13 \%$ & $222.73 \%$ & $122.20 \%$ & $17.37 \%$ \\
\hline & 2020 & $89.40 \%$ & $105.10 \%$ & $-0.43 \%$ & $101.98 \%$ & $2.50 \%$ & $100.59 \%$ & $246.94 \%$ & $133.75 \%$ & $26.38 \%$ \\
\hline & 2030 & $81.08 \%$ & $104.35 \%$ & $-2.02 \%$ & $96.93 \%$ & $2.78 \%$ & $99.07 \%$ & $305.60 \%$ & $162.55 \%$ & $26.65 \%$ \\
\hline \multirow[t]{5}{*}{ Scenario 6} & 2007 & $100.00 \%$ & $100.00 \%$ & $6.17 \%$ & $100.00 \%$ & $2.61 \%$ & $100.00 \%$ & $170.38 \%$ & $100.00 \%$ & $14.90 \%$ \\
\hline & 2010 & $98.63 \%$ & $101.30 \%$ & $5.59 \%$ & $101.82 \%$ & $2.51 \%$ & $100.54 \%$ & $186.51 \%$ & $107.95 \%$ & $15.83 \%$ \\
\hline & 2015 & $90.47 \%$ & $99.60 \%$ & $7.84 \%$ & $90.56 \%$ & $3.15 \%$ & $97.07 \%$ & $225.78 \%$ & $121.38 \%$ & $17.37 \%$ \\
\hline & 2020 & $88.56 \%$ & $104.12 \%$ & $-1.65 \%$ & $98.84 \%$ & $2.67 \%$ & $99.65 \%$ & $235.22 \%$ & $126.26 \%$ & $26.74 \%$ \\
\hline & 2030 & $81.28 \%$ & $104.60 \%$ & $-5.45 \%$ & $97.71 \%$ & $2.73 \%$ & $99.31 \%$ & $251.16 \%$ & $133.71 \%$ & $26.89 \%$ \\
\hline \multirow[t]{5}{*}{ Scenario 7} & 2007 & $100.00 \%$ & $100.00 \%$ & $6.17 \%$ & $100.00 \%$ & $2.61 \%$ & $100.00 \%$ & $170.51 \%$ & $100.00 \%$ & $14.90 \%$ \\
\hline & 2010 & $98.63 \%$ & $101.30 \%$ & $5.59 \%$ & $101.82 \%$ & $2.51 \%$ & $100.54 \%$ & $186.73 \%$ & $107.99 \%$ & $15.83 \%$ \\
\hline & 2015 & $90.49 \%$ & $99.63 \%$ & $8.14 \%$ & $90.63 \%$ & $3.15 \%$ & $97.09 \%$ & $226.46 \%$ & $121.67 \%$ & $17.37 \%$ \\
\hline & 2020 & $88.55 \%$ & $104.11 \%$ & $-1.31 \%$ & $98.80 \%$ & $2.67 \%$ & $99.64 \%$ & $237.98 \%$ & $127.50 \%$ & $26.74 \%$ \\
\hline & 2030 & $81.19 \%$ & $104.49 \%$ & $-4.99 \%$ & $97.37 \%$ & $2.75 \%$ & $99.20 \%$ & $259.50 \%$ & $136.54 \%$ & $26.92 \%$ \\
\hline
\end{tabular}




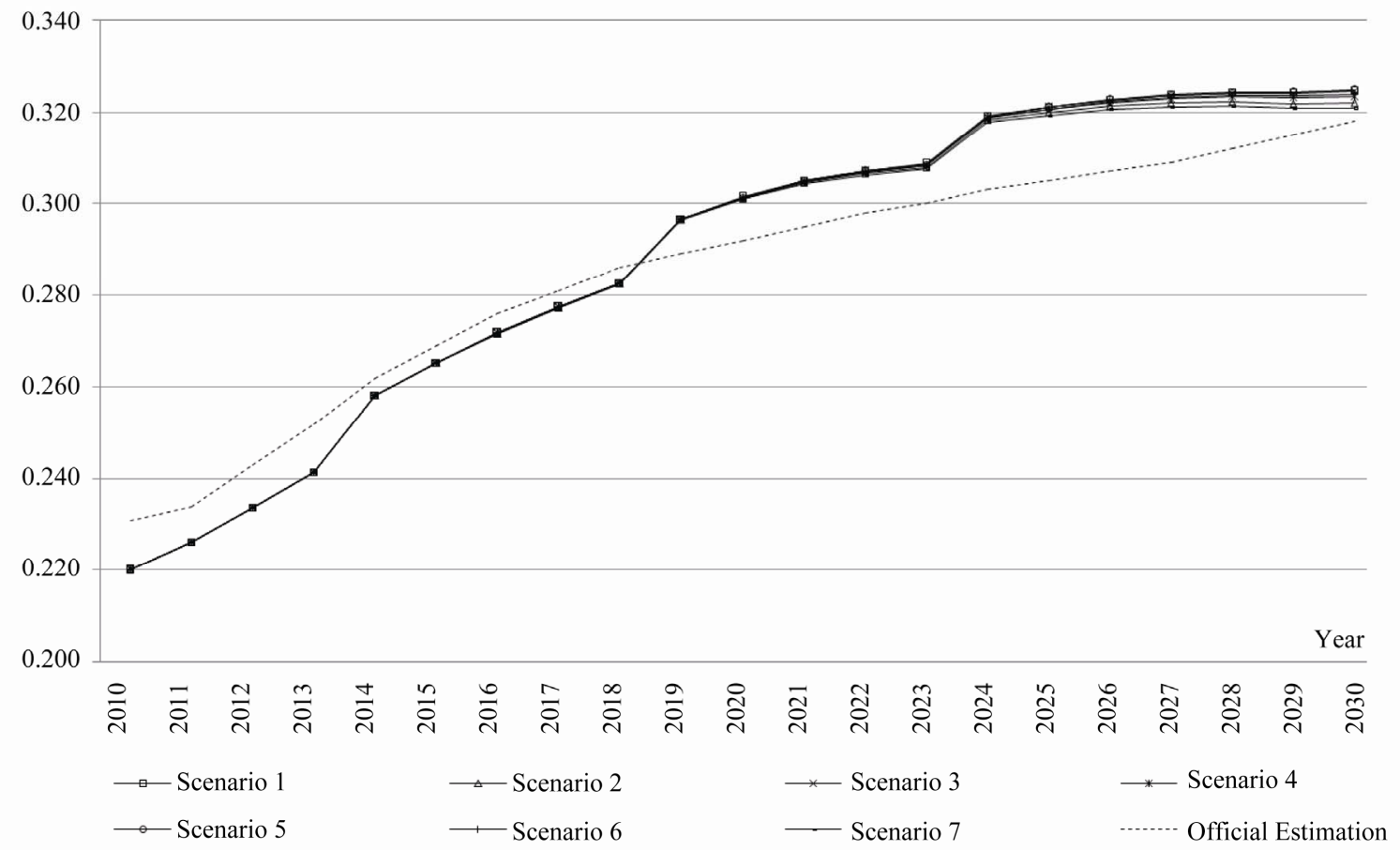

Figure 3. Simulation Results - Retired population ratio.

Security Research [24], closely correspond. In Scenario 2, compared with Scenario 1, the ratio in 2030 decreases by $0.3 \%$, in Scenario 3 by $0.03 \%$, and in Scenario 4 by $0.14 \%$. Thus it can be seen that these child benefit expansions slightly decrease the progress of population aging.

As we adopt the lifecycle hypothesis, the saving rate is severely affected by the rise of the rate of elderly population, which is strongly correlated with the demographic trend. In Scenarios 1 to 7, there is no significant change in the trend of the saving rate during the simulation periods. But its level differs in each scenario. In Scenario 1, the saving rate shows a tendency to decrease from $6.17 \%$ in 2007 to $1.16 \%$ in 2030. Table 4 shows that the child benefit expansions basically raise the saving rate in 2007 to 2030 years. On the other hand, the reform with higher consumption tax reduces the saving rate more in the years from 2007 to 2030 .

Because of the assumed technology and lifecycle hypothesis, the GDP is determined mainly by working-age population dynamics. In the baseline scenario, the GDP level grows stagnant. It declines markedly from 2020 to 2030, reflecting the declining labor force. And then, in each scenario, the GDP declines to $80.66 \%-81.28 \%$ in 2030 from the base year 2007. But, in Scenarios 1 to 5, GDP per employee increases from 2007 to 2030 . On the other hand, in Scenarios 6 and 7, GDP per employee temporally decreases in 2015 and increases after 2020.

Finally, we briefly valuate factor prices. In each sce- nario, due to the capital market equilibrium, the interest rate (wage rate) fluctuates within a narrow range, e.g., $2.32 \%-2.87 \%(98.56 \%-101.65 \%)$ over three decades.

\subsection{Fiscal Variables}

Generally, the child benefit expansion can be expected to give the fiscal balance ambivalent effects through several channels. If the expansion is financed by new public bond issues, it initially increases public debt. But the increase in the number of children also increases tax bases, and then changes the trend of government revenue and expenditure. As a result, the future government debt will be either reduced or increased.

Table 4 shows that in Scenario 2, compared with Scenario 1, the Debt-GDP ratio slightly increases by $6.99 \%$ in 2030 . In Scenario 3, the ratio increases by $5.05 \%$ in 2030, and in Scenario 4 by $3.30 \%$. Figure 4 also shows that in Scenario 2 compared with Scenario 1, the debt per employee slightly increases by 0.01 in 2030, in Scenario 3 by 0.02 in 2030 and in Scenario 4 by 0.01 in 2030.

On the other hand, in Scenarios 5 to 7 (consumption tax reform or policy-mix), the Debt-GDP ratio is reduced by $58.80 \%-113.23 \%$ in 2030 , and the debt per employee is reduced by $0.28-0.55$ in 2030 .

\subsection{Welfare}

Figure 5 shows generational welfares of Scenarios 1 to 7 . 


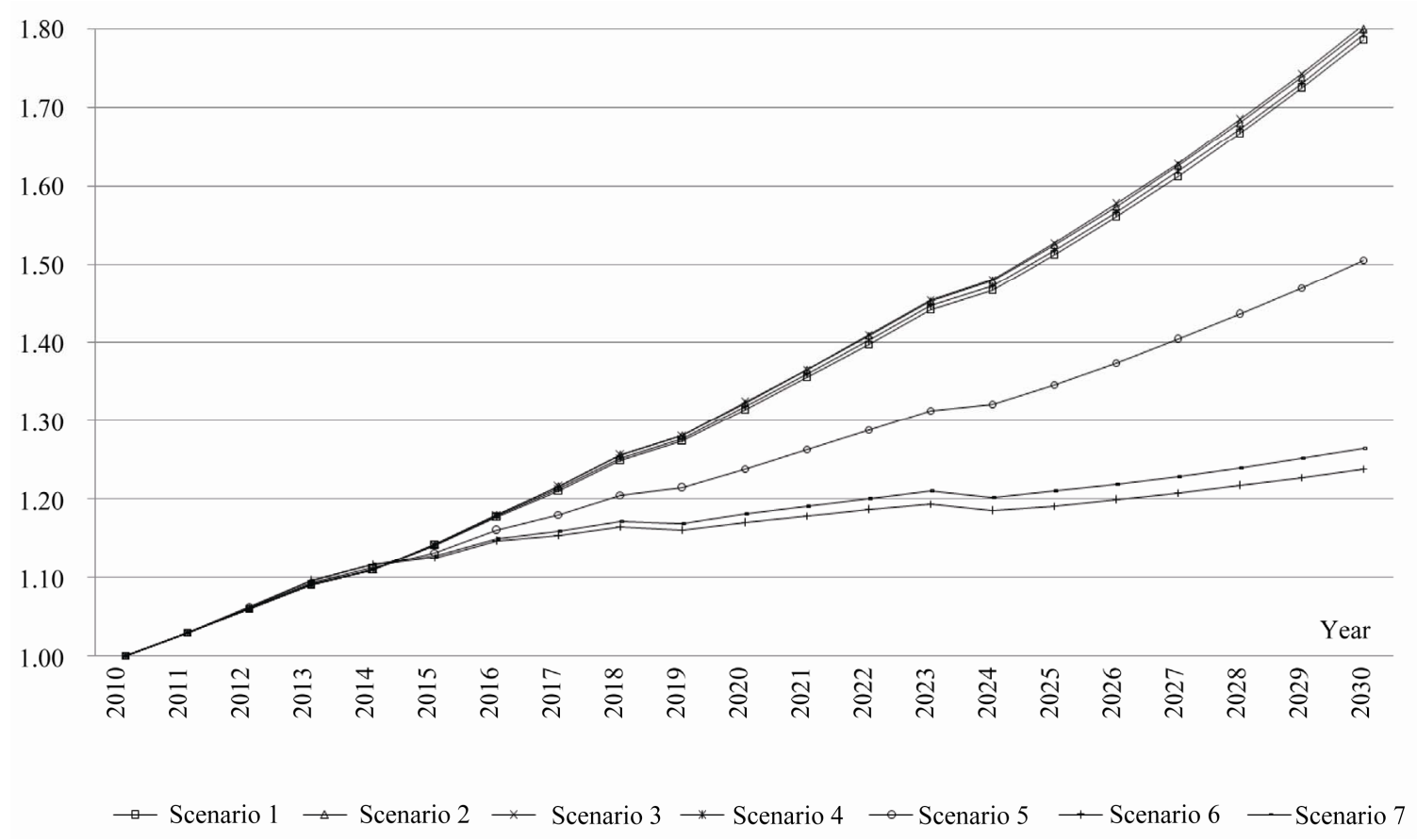

Figure 4. Simulation Results - Debt per employee.

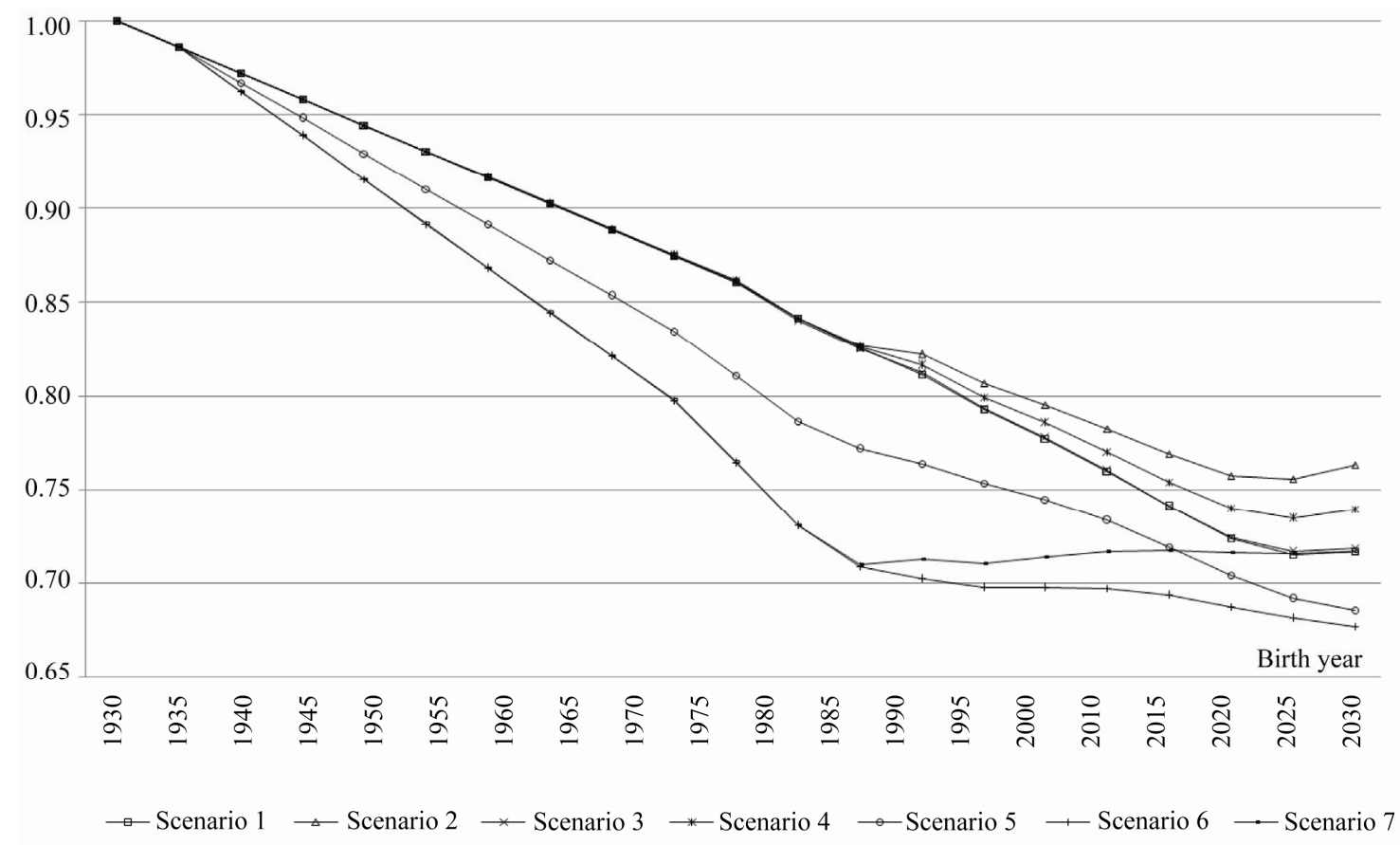

Figure 5. Simulation Results - Welfare with Equivalent Variation.

These are welfares of subsequent cohorts measured in terms of lifetime utility level against the cohort born in 1930. The long-run increase in the pension premium to wage rate caused by the progress of aging decreases the amount of resources available within their lifetime. The long-run increase in the public debt to GDP ratio also reduces private capital stock available and possibly decreases future growth. Current and future generations suffer a severe welfare loss.

In Scenarios 1 to 7 in Figure 5, we measure the welfare of each generation with equivalent variation. The welfares of Scenario 5 and 6 gradually decline and the 
bottom for this scenario doesn't occur until birth year 2030, but Scenarios 1 to 4 have a welfare bottom at the generation born in 2025, and the bottom for Scenario 7 is in 1990 .

In addition, in Scenarios 2 to 4, compared with Scenario 1, all generations born after 1990 obtain a welfare gain: e.g., in Scenario 2, the welfare of the generation born in 2030 dramatically increases by $4.6 \%$, in Scenario 3 by $0.2 \%$, and in Scenario 4 by $2.2 \%$. This means that the welfare conditions in Scenarios 2 to 4 correspond to the concept of "RC-improvement" developed by Michel and Wigniolle [7].

On the other hand, in Scenarios 5 to 7, compared with Scenario 1, most generations born after 1940 suffer a welfare loss whose burden is covered by an increase in consumption tax. However, if Scenario 6 is an inevitable choice in order to maintain the sustainability of fiscal budget, we should change the baseline scenario from Scenario 1 to Scenario 6. Then, in Scenario 7, compared with Scenario 6, all generations born after 1990 obtain a welfare gain. This means that Scenario 7 also becomes an "RC-improvement."

Therefore, from the comparison between the child benefit scenarios, the consumption tax reform scenarios, and the policy-mix scenario, we draw the following conclusions: 1) if we can ignore the sustainability of the fiscal budget in Scenarios 2 to 4, the child benefit expansions are expected to make some contributions to the improvement of the welfare of current and future generations, and 2) if both the sustainability of the fiscal budget and the improvement of the welfare of current and future generations are requirements, we will need to promote a policy such as a policy-mix with the child benefit expansion and additional fiscal reform, i.e. increasing the consumption tax. Then, the policy-mix can be expected to provide a higher level of welfare for current and future generations than only consumption tax reform.

\section{Concluding Remarks}

In this paper, we presented an OLG simulation model with endogenous fertility in order to analyze the relationship between child benefit and fiscal burden in Japan. Our simulation results show that expansion of the child benefit will improve the welfare of current and future generations. On the other hand, our findings show that we cannot expect a significant long-term improvement in welfare solely from implementing a policy of increasing the consumption tax. If both the sustainability of the fiscal budget and the improvement of the welfare of current and future generations are requirements, we will need to promote a strategy consisting of such components as a policy-mix that includes both child benefit expansion and additional fiscal reform, i.e. increasing the consumption tax. Implementation of such a the policy-mix can be expected to provide a higher economic level in the welfare of current and future generations could be expected solely from consumption tax reform.

In addition, the Japanese government is currently trying to develop a model for estimating the direction of the population of future generations, which has economic underpinnings. Therefore, if our model can be made more robust, it may prove to have a great impact on the method for estimation of the Japanese population, by which we analyze the relationship between future population and changes in the economic environment.

Finally, in an era of population aging, Japan will face enormous difficulties. Even given the difficulty of the task, Japan, like other developed countries, must confront these and other obstacles and solve the related issues to chart a productive and viable future for its future generations.

\section{References}

[1] P. A. Diamond, "National Debt in a Neoclassical Growth Model," American Economic Review, Vol. 55, No. 5, 1965, pp. 1126-1150.

[2] A. B. Abel, N. G. Mankiw, L. H. Summers and R. J. Zeckhauser, "Assessing Dynamic Efficiency: Theory and Evidence," Review of Economics Studies, Vol. 56, No. 1, 1989, pp. 1-20.

[3] L. K. Raut and T. N. Srinivasan, "Dynamics of Endogenous Growth," Economic Theory, Vol. 4, No. 5, 1994, pp. 777-790

[4] R. Chakrabarti, "Endogenous Fertility and Growth in a Model with Old Age Support," Economic Theory, Vol. 13, No. 2, 1999, pp. 393-416.

[5] J. I. Conde-Ruiz, E. L. Gimenez and M. Perez-Nievas, "Millian Efficiency with Endogenous Fertility," Review of Economic Studies, Vol. 77, No. 1, 2010, pp. 154-187.

[6] M. Golosov, L. E. Jones and M. Tertilt, "Efficiency with Endogenous Population Growth," Econometrica, Vol. 75, No. 4, 2007, pp. 1039-1071.

[7] P. Michel and B. Wigniolle, "On Efficient Child Making," Economic Theory, Vol. 31, No. 2, 2007, pp. 307326.

[8] G. S. Becker, "An Economic Analysis of Fertility. In: National Bureau of Economic Research, Ed., Demographic and Economic Change in Developed Countries," National Bureau of Economic Research, Inc., Princeton, 1960, pp. 209-231.

[9] R. Willis, "A New Approach to the Economic Theory of Fertility Behavior," Journal of Political Economy, Vol. 81, No. 2, 1973, pp. 14-64.

[10] Z. Eckstein and K. Wolpin, "Endogenous Fertility and Optimal Population Size," Journal of Public Economics, Vol. 27, No. 1, 1985, pp. 93-106. 
[11] G. S. Becker and R. J. Barro, "A Reformulation of the Economic Theory of Fertility," Quarterly Journal of Economics, Vol. 103, No. 1, 1988, pp. 1-25.

[12] K. Nishimura, and J. Zhang, "Pay-As-You-Go Public Pensions with Endogenous Fertility," Journal of Public Economics, Vol. 48, No. 2, 1992, pp. 239-258.

[13] K. Oguro and J. Takahata, "Child Benefit and Fiscal Burden with Endogenous Fertility," Discussion Papers on Demography and Policy, No. 2009-001, 2009, Public Economics Program, School of International and Public Policy, Hitotsubashi University.

[14] B. V. Groezen, T. Leers and L. Meijdam, "Social Security and Endogenous Fertility: Pensions and Child Allowances as Siamese Twins," Journal of Public Economics, Vol. 87, No. 2, 2003, pp. 233-251.

[15] A. J. Auerbach and L. J. Kotlikoff, "Dynamic Fiscal Policy," Cambridge University Press, Cambridge, 1987.

[16] A. Sadahiro and M. Shimasawa, "Fiscal Sustainability and the Primary Surplus: A Simulation Analysis with OLG Model," JCER Economic Journal, Vol. 43, No. 2, 2001, pp.117-132.

[17] A. Sadahiro and M. Shimasawa, "The Computable Overlapping Generations Model with an Endogenous Growth Mechanism," Economic Modeling, Vol. 20, No. 1, 2003, pp. 1-24.

[18] T. Uemura, "Lifecycle General Equilibrium Analysis on Social Security," Keizaironshu, Vol. 28, No. 1, 2002, pp.
$15-36$.

[19] T. Ihori, R. Kato, M. Kawade and S. Bessho, "Public Debt and Economic Growth in an Aging Japan. In: Kaizuka, K. and Krueger, A. O. Ed.," Tackling Japan's Fiscal Challenges: Strategies to Cope with High Public Debt and Population Aging, Palgrave Macmillan, New York, 2006, pp. 30-68.

[20] OECD Tax Database, 2007.

http://www.oecd.org/document/60/0,3746,en_2649_3453 3_1942460_1_1_1_1,00.html

[21] Whitehouse, "E. Pensions Panorama: Retirement-Income Systems in 53 Countries," World Bank, Washington D. C., 2007.

[22] National Institute of Population and Social Security Research Population Statistics of Japan, 2007. http://www.ipss.go.jp/syoushika/tohkei/Popular/Popular2 007.asp?chap $=0$

[23] Cabinet Office Director-General for Policies on a Cohesive Society, Japan, Shakai Zentai no Kosodate Hiyo ni kansuru Chosa Kenkyu Hokokusho, 2005.

http://www8.cao.go.jp/shoushi/cyousa/cyousa16/kosodate /index_pdf.html

[24] National Institute of Population and Social Security Research, Population Projections for Japan: 2006-2055. 2006.

http://www.ipss.go.jp/syoushika/tohkei/suikei07/index.asp 